\title{
Accessible Player Experiences (APX): The Players
}

\author{
Jen Beeston ${ }^{1(凶)}\left([)\right.$, Christopher Power ${ }^{1,2}(\mathbb{1})$, Paul Cairns ${ }^{1,2}(\mathbb{D}$, \\ and Mark Barlet ${ }^{2}$ \\ ${ }^{1}$ Department of Computer Science, University of York, Deramore Lane, \\ Heslington, York YO10 5GH, UK \\ jen.beeston@york.ac.uk \\ 2 The AbleGamers Foundation, PO Box 508, Charles Town, WV 25414, USA
}

\begin{abstract}
In research and practice into the accessibility of digital games, much of the work has focused on how to make games accessible to people with disabilities. With an increasing number of people with disabilities playing mainstream commercial games, it is important that we understand who they are and how they play in order to take a more user-centered approach as this field grows. We conducted a demographic survey of 154 players with disabilities and found that they play mainstream digital games using a variety of assistive technologies, use accessibility options such as key remapping and subtitles, and they identify themselves as gamers who play digital games as their primary hobby. This gives us a richer picture of players with disabilities and indicates that there are opportunities to begin to look at the accessible player experiences (APX) players have in games.
\end{abstract}

Keywords: Digital games · Accessibility $\cdot$ Disability

\section{Introduction and Background}

Currently, video games represent a significant part of our everyday modern lives, with $\mathrm{UKIE}^{1}$ estimating that between 2.2 and 2.6 billion people play digital games worldwide. From online activity in social media, Twitch and player communities, we know that players with disabilities are increasingly part of what is a dynamic and growing community of digital game players, however there is very sparse research into who they are as players, the types of games they play and the prevalence of use of assistive technologies and accessibility settings in games. We surveyed 154 players with disabilities collected as part of the AbleGamers Player Panels programme, to direct future research as to the diversity of this distinctive population of players, and to inform design in terms of the diversity of breadth of technologies that are currently being used in digital games.

Researchers and designers alike acknowledge that there are not only barriers to playing digital games, but also accessibility concerns within the games themselves for those with individual and complex needs. Previously, researchers have considered the

\footnotetext{
${ }^{1}$ http://ukie.org.uk/research.

(C) The Author(s) 2018

K. Miesenberger and G. Kouroupetroglou (Eds.): ICCHP 2018, LNCS 10896, pp. 245-253, 2018. https://doi.org/10.1007/978-3-319-94277-3_40
} 
barriers that players with disabilities encounter in games, with their efforts focused mainly on how technology can be adapted to enable them to play [1] and on creating bespoke games to investigate how games can be made playable for players with varying disabilities $[9,14]$. Alongside this research, several charity organizations (e.g. AbleGamers, Gamers Outreach, Special Effect) and advocates of disabled gaming have established community and support for players with disabilities and created information to guide game developers to make adaptations and improvements [3]. Following on from this work, the successful integration of accessibility into many commercial titles means there are many people with disabilities playing online amidst non-disabled players. However, little is known about this audience and their player experiences. It is currently unclear what, if any, technology and accessibility options are being used by players with disabilities. Some academics have found that various methods that can be used to enable play, such as controllers [5], skill assistance [7] and difficulty adjustments [2] may impact upon the experience of play for those using them. For players with disabilities who may use these to play it is important to consider what effect this has on their experiences in games and in the social elements of the gaming hobby.

Digital games are widely recognised as a popular, enjoyable and even beneficial activity from which players can derive a sense of wellbeing [10]. Therefore, it is important that access to games should be universal and should not exclude people with disabilities. Most players view games as an end in themselves that provide experiences that are intrinsically valued [12]. However, rather than thinking about how players with disabilities play mainstream games that everyone plays, games are often positioned as a means to an end, particularly for rehabilitation and research is often focussed on creating bespoke games [9] or adapting and creating novel controllers [14]. This approach neglects the evidence that there are growing numbers of disabled players playing mainstream games alongside everyone else. Digital games are supporting real inclusion but little is known about how disabled players are gaining access to games and the experiences they have when they are playing, whether valued or not.

If we are to move research and practice beyond questions of basic access and enablement [16] it is important that we know more about players in the game space so we can begin to understand their accessible player experiences (APX) in games. Porter and Kientz [15] provide a useful starting point with a survey of 55 players with disabilities collected age, gender, impairment class, platforms played on, and types of games played and was also supplemented by interviews. They found that their participants had some incompatibilities with technologies that were barriers to their gaming, and that their sample tended towards single player games and less towards multiplayer games. Additionally, they spoke to games industry professionals about their current practises in making games accessible for players with disabilities. Their findings suggest that the games industry focus on the things that they are immediately aware of, such as a colleague having a specific need, such as colour remapping or subtitles. The motivation of the work reported in this paper is to provide a more comprehensive understanding of players with disabilities to inform and extend the focus of subsequent research and practice into accessible games. 


\section{Method}

The AbleGamers Player Panels programme was created in a collaboration between the University of York and the AbleGamers Charity to provide a systematic means by which players with disabilities can have a voice in digital games research and development. The aim of the programme is to facilitate organisations looking to do user research or games testing with players with disabilities by putting them in touch with suitable players who have already declared an interest in taking part in such research. To enable such matchmaking and also to provide a better understanding of players with disabilities, the aim of this study is the collection of the necessary demographic information about the players.

The demographic survey was iteratively developed with collaboration between the AbleGamers team and players with disabilities. Players originally registered interest in the Player Panels through the AbleGamers Charity website, where they provided a small amount of demographic information including: contact information, age, current gaming platforms used, game genres played, and their motivation to register. The AbleGamers Player Panels registration requested that players only register if they want to be involved and be contacted by researchers and developers, have access to the internet and could fill out the online survey. The demographic questionnaire was available for all ages and for those with any form of disability that did not prevent them from completing the online questionnaire. This work and further research only included participants over the age of 18 and excluded those who have indicated that they have a cognitive disability. This was to safeguard those for whom consent could not be guaranteed at this stage.

A sample of 7 respondents from the California area took part in a telephone interview to trial further demographic questions and to inform questions about their gaming habits. From this, an initial draft demographic questionnaire was created and feedback elicited from 5 further registered respondents and from AbleGamers staff.

The final demographic survey contained demographic information, such as their contact information, preferences, gaming needs, current habits and technology usage, which can be used to identify participants for opportunities with organisations. Further, participants gave consent for the information to be used by AbleGamers and their partners for purposes of research.

\section{Results}

\subsection{About the Players}

Out of 154 respondents, 92 people identified as male, 38 female, 15 non-binary and 9 preferred not to say. The average age of respondents was 32 . When asked about the length of a typical play session for them, 74 respondents said they played between 2 to $4 \mathrm{~h}$ at a time; 39 played 1 to 2 h, 32 played 5 h or more, and only 9 people reported a typical session as being $1 \mathrm{~h}$ or less. Respondents were asked to select as many of the items in Table 1 to describe their disabilities as required. It is worth noting that 'Other needs and preferences' was an open text item. This mainly seems to have been used to 
provide a more detailed description or the medical terms for their disability. To retain confidentiality, this information is not provided here.

Table 1. Disability information

\begin{tabular}{l|l}
\hline Disability & Respondents \\
\hline Autism & 18 \\
\hline Hard of hearing & 20 \\
\hline Deaf & 7 \\
\hline Upper limb physical disabilities & 91 \\
\hline Lower limb physical disabilities & 81 \\
\hline Mental Health Difficulties & 41 \\
\hline Learning Disabilities (e.g. dyslexia, SLP, ADHD, language etc.) & 26 \\
\hline Blind & 8 \\
\hline Colour vision deficient (e.g. red-green colour blind) & 6 \\
\hline Low vision & 25 \\
\hline Other needs and preferences & 42 \\
\hline &
\end{tabular}

Many of the respondents identified themselves as gamers (96) and consider it to be their primary hobby (87). There were an almost equal number of people who considered themselves to be hardcore gamers (46) as those who identified as casual gamers (47). Very few people did not consider themselves a gamer (16) or only played games when they have nothing else to do (10).

\subsection{What Are They Playing?}

The gaming platforms rated as being used 'very often' by respondents were PC (104), followed by phone (53), PlayStation (52), Nintendo Switch (26), Xbox (24), then tablet (20). Out of those platforms, Nintendo Switch scored highest in the 'do not play' category, followed by Xbox, tablet, PlayStation, Phone, and then PC. It is quite possible that Nintendo Switch was least played since it was the newest gaming console listed in the options. The game types selected as played most often were Single Player (124), followed by Online Multiplayer (72), Cooperative Multiplayer (52), Competitive Multiplayer (40), One vs. One Multiplayer (26), and then Local multiplayer (17). Respondents were asked to provide their top 3 current favourite games. There were 255 different titles provided. Where games received more than one entry, a top favourite games list was created to show which were the most popular games (Table 2). 
Table 2. Top favourite games

\begin{tabular}{l|l|l|l}
\hline Rank & Top favourite games & Respondents & $\begin{array}{l}\text { Best-selling games of 2017 by } \\
\text { NPD Group }\end{array}$ \\
\hline 1 & Destiny 2 & 13 & Call of Duty: WWII \\
\hline 2 & Overwatch & 9 & Star Wars: Battlefront II \\
\hline 4 & Super Mario Odyssey & 9 & Super Mario Odyssey \\
\hline 5 & $\begin{array}{l}\text { PlayerUnknown's } \\
\text { Battlegrounds }\end{array}$ & 8 & NBA 2K18 \\
\hline 6 & The Legend of Zelda: Breath of \\
the Wild & 8 & Mario Kart 8 \\
\hline 8 & World of Warcraft & 8 & Madden NFL 18 \\
\hline 9 & The Elder Scrolls V: Skyrim & 7 & PlayerUnknown's Battlegrounds \\
\hline 9 & Hearthstone Duty World War II & 6 & Assassin's Creed: Origins \\
\hline 10 & Rocket League & 6 & $\begin{array}{l}\text { The Legend of Zelda: Breath of } \\
\text { the Wild }\end{array}$ \\
\hline 11 & Stardew Valley & 6 & Grand Theft Auto V \\
\hline
\end{tabular}

Source of ranked list: https://venturebeat.com/2018/01/18/december-npd-2017-nintendoswitch-leads-the-hardware-pack-in-a-3-29-billion-month/.

Note: Please see footnotes 2 in Sect. 4 for further top games lists by platform.

\subsection{How Are the Players Accessing Games?}

Participants were asked to indicate whether they used any items from a selection of assistive technologies (hardware) and accessibility options (software) or could specify in separate textbox if they used something not listed. Of the assistive technologies, 24 respondents provided information in the 'other' box. Items such as on-screen keyboard and using a converter to use keyboard and mouse on console were mentioned. One respondent mentioned that they used a handheld magnifying glass, but they did not specify exactly what they used this for. Customized controllers or alternative PC mouse were also selected as often used assistive technologies. Popular accessibility options items used were subtitles and key remapping/bindings used by 83 respondents (Table 3).

Table 3. Assistive gaming technology and in-game accessibility options

\begin{tabular}{l|c|l|l}
\hline Assistive technology & Respondents & Accessibility options & Respondents \\
\hline Eye gaze tracking & 2 & Text to speech & 11 \\
\hline Customized controller & 18 & Speech to text & 17 \\
\hline One handed controller & 3 & Subtitles & 83 \\
\hline Screen reader & 9 & Colour blind options & 7 \\
\hline Alternative PC mouse & 17 & Contrast or colour changes & 29 \\
\hline VR headset & 3 & Mouse cursor enlargement & 24 \\
\hline Alternative controller & 7 & Text enlargement & 44 \\
\hline Other technology & 24 & Auditory or screen alerts & 24 \\
\hline & & Key remapping & 83 \\
\hline & & Other option & 23 \\
\hline
\end{tabular}




\section{Discussion}

The results show that this sample of players with disabilities are choosing to play mainstream, commercial games. Many of their favourite current games are aligned with current, top/most played games across the common gaming platforms ${ }^{2}$ which strongly suggests that the gaming preferences of these players is no different from non-disabled digital game players. While this aligns with Porter and Kientz [15], Flynn and Lange [8] regarding the desire of players to play mainstream AAA titles, we differ in that our sample shows that more than half of our players favourite games are multiplayer games. Whether this is due to sampling bias, or due to a shift in demographics since that previous work, we have compelling evidence that players are engaging in both single player games, and online, community-based play.

Our findings show that there are some adaptations that are commonly used among this sample, such as customised controllers/PC mouse, subtitles and key remapping. This suggests that even such minimal accommodations provided in games can help to enable play for many players. PC was the most used gaming platform by participants. This is consistent with common wisdom that until recently PC gaming was more accessible than consoles as accessibility is more mature on that platform [15]. It will be important to revisit this in the near future now that a number of consoles are integrating middleware solutions for accessibility. Phone was the second most used platform by respondents which may be due to the ubiquity of the smartphone in modern life which is something that people are likely to own anyway rather than a separate platform for gaming.

Many of these players consider themselves to be gamers, and a substantial portion say that they are hardcore gamers which suggests that they identify deeply with the gaming hobby and invest substantial time and effort on the hobby [6]. If this is the case, there are social aspects to consider for these players within gaming, too. Previous studies suggest that features such as aim assist, difficulty settings, or different controllers can impact how players view not only their own ability and play experiences, but other players as well.

It is important to note that this sample of disabled players is likely subject to selection bias: these are players who currently play digital games and could complete our survey. As this survey was conducted to gain an overview of the AbleGamers Player Panels community, there are items which were not covered initially that could form the basis of further work. This may include covering: what assistive technologies or accessibility options/software players feel that they do not have but would help them, a broader look at what gaming platforms may be used (e.g. older consoles such as Nintendo Wii), a deeper look at who they are playing with and what their online multiplayer experiences are like.

More importantly, even though there will likely always be a need to address the implementation lag of new technologies to provide accessible options [16], we see that

\footnotetext{
2 https://www.polygon.com/2018/1/5/16853706/ps4-games-top-psn-downloads-destiny-gta, http:// store.steampowered.com/stats/, http://comicbook.com/gaming/2018/01/06/most-played-nintendoswitch-games/, https://www.microsoft.com/en-gb/store/most-played/games/xbox.
} 
commercial mainstream games are reaching a point in the research domain where there is the opportunity to move beyond simply providing access to games. There is the opportunity to explore what it means for players to have accessible player experiences within games, leveraging the existing wealth of knowledge from the player experience research community.

\section{Conclusions}

The demographic survey we conducted shows that our participants are much like samples of the wider population of players. They are playing mainstream games, they identify as 'gamers' and give substantial amounts of their free time to the hobby. Since previous research has focussed on using games for therapeutic uses and rehabilitation, this work shows that, this may not be the only reason disabled people play games. Additionally, there may still be issues with control mechanisms for disabled players and mainstream games may not be entirely accessible, however despite this, there are still disabled players who do have access and do play mainstream games. Therefore, game designers and researchers can assume that people with disabilities want to play mainstream games with everyone else and will attempt to find a way to play. In terms of game design, since many of these players have reported using adaptations such as auditory alerts, key remapping, subtitles, alternative controllers, screen readers, this suggests that these minimal additions and modifications to games can accommodate for a substantial audience of disabled players. As such, it is becoming increasingly important for researchers and designers to consider not only the effectiveness of these adaptations but how these impact their overall APX of play and, consequently, their social experiences in playing games with others.

Acknowledgments. Thanks to the AbleGamers Charity for the collaboration on the Player Panels programme, and all the players who volunteered their time. This work is funded by EPSRC grant [EP/L015846/1] (IGGI) and the University of York Research Priming Fund.

\section{References}

1. Archambault, D., Gaudy, T., Miesenberger, K., Natkin, S., Ossmann, R.: Towards generalised accessibility of computer games. In: Pan, Z., Zhang, X., El Rhalibi, A., Woo, W., Li, Y. (eds.) Edutainment 2008. LNCS, vol. 5093, pp. 518-527. Springer, Heidelberg (2008). https://doi.org/10.1007/978-3-540-69736-7_55

2. Baldwin, A., Johnson, D., Wyeth, P.: Crowd-pleaser: player perspectives of multiplayer dynamic difficulty adjustment in video games. In: Proceedings of the 2016 Annual Symposium on Computer-Human Interaction in Play, pp. 326-337. ACM (2016)

3. Barlet, M.C., Spohn, S.D.: Includification: A Practical Guide to Game Accessibility. The Ablegamers Foundation, Charles Town (2012)

4. Bierre, K., Chetwynd, J., Ellis, B., Hinn, D. M., Ludi, S., Westin, T.: Game not over: accessibility issues in video games. In: Proceedings of the 3rd International Conference on Universal Access in Human-Computer Interaction, pp. 22-27 (2005) 
5. Birk, M., Mandryk, R.L.: Control your game-self: effects of controller type on enjoyment, motivation, and personality in game. In: Proceedings of the SIGCHI Conference on Human Factors in Computing Systems, pp. 685-694. ACM, April 2013

6. Bosser, A.G., Nakatsu, R.: Hardcore gamers and casual gamers playing online together. In: Harper, R., Rauterberg, M., Combetto, M. (eds.) ICEC 2006. LNCS, vol. 4161, pp. 374 377. Springer, Heidelberg (2006). https://doi.org/10.1007/11872320_53

7. Depping, A.E., Mandryk, R.L., Li, C., Gutwin, C., Vicencio-Moreira, R.: How disclosing skill assistance affects play experience in a multiplayer first-person shooter game. In: Proceedings of the 2016 CHI Conference on Human Factors in Computing Systems, pp. 3462-3472. ACM, May 2016

8. Flynn, S., Lange, B.: Games for rehabilitation: the voice of the players. In; International Conference on Disability, Virtual Reality \& Associated Technologies (ICDVRAT 2010), pp. 185-194 (2010)

9. Grammenos, D., Savidis, A., Georgalis, Y., Stephanidis, C.: Access invaders: developing a universally accessible action game. In: Miesenberger, K., Klaus, J., Zagler, Wolfgang L., Karshmer, Arthur I. (eds.) ICCHP 2006. LNCS, vol. 4061, pp. 388-395. Springer, Heidelberg (2006). https://doi.org/10.1007/11788713_58

10. Jones, C.M., Scholes, L., Johnson, D., Katsikitis, M., Carras, M.C.: Gaming well: links between videogames and nourishing mental health. Front. Psychol. 5, 260 (2014)

11. Juul, J.: A Casual Revolution: Reinventing Video Games and Their Players, pp. 8-12. MIT press (2010)

12. Juul, J.: Half-Real: Video Games Between Real Rules and Fictional Worlds. MIT press, Cambridge (2011)

13. Kulshreshth, A., LaViola, Jr., J.J.: Evaluating performance benefits of head tracking in modern video games. In: Proceedings of the 1st Symposium on Spatial User Interaction, pp. 53-60. ACM (2013)

14. López, S.A., Corno, F., Russis, L.D.: Design and development of one-switch video games for children with severe motor disabilities. ACM Trans. Accessible Comput. (TACCESS) 10(4), 12 (2017)

15. Porter, J.R., Kientz, J.A.: An empirical study of issues and barriers to mainstream video game accessibility. In: Proceedings of the 15th International ACM SIGACCESS Conference on Computers and Accessibility, p. 3. ACM, October 2013

16. Power, C., Cairns, P., Barlet, M.: Inclusion in the third wave: from access to experience. In: New Directions in the Third Wave of HCI. Springer (to appear)

17. Sherry, J.L., Lucas, K., Greenberg, B.S., Lachlan, K.: Video game uses and gratifications as predictors of use and game preference. Playing video games: motives, responses, and consequences 24(1), 213-224 (2006) 
Open Access This chapter is licensed under the terms of the Creative Commons Attribution 4.0 International License (http://creativecommons.org/licenses/by/4.0/), which permits use, sharing, adaptation, distribution and reproduction in any medium or format, as long as you give appropriate credit to the original author(s) and the source, provide a link to the Creative Commons license and indicate if changes were made.

The images or other third party material in this chapter are included in the chapter's Creative Commons license, unless indicated otherwise in a credit line to the material. If material is not included in the chapter's Creative Commons license and your intended use is not permitted by statutory regulation or exceeds the permitted use, you will need to obtain permission directly from the copyright holder. 